\title{
A Study of Adolescents Who Provide Tobacco to Other Adolescents in a Racial/Ethnic Diverse Population
}

\author{
Steven E. Shive ${ }^{1}$, Grace X. Ma ${ }^{2}$, Patricia M. Legos ${ }^{2}$, Earl S. Shive ${ }^{1}$ \\ ${ }^{1}$ East Stroudsburg University \\ ${ }^{2}$ Temple University
}

\begin{abstract}
This study examined the sources of tobacco and the adolescent provision of tobacco to other adolescents in an ethnically/racially diverse, large heterogeneous urban, adolescent population in Philadelphia, Pennsylvania. A stratified multistage purposive sampling procedure was used to select an ethnically/racially diverse sample, which consisted of 569 students in grades 8-10 in five public and nonpublic funded schools. A logistical regression analysis was used to examine potential predictor variables of adolescent provision of tobacco to other adolescents. Social sources of tobacco were more common than commercial. Gas stations/convenience stores, grocery stores, recreational/sports centers, and pharmacies were the most reported commercial sources. Among adolescent smokers, $46 \%$ of smokers gave tobacco to another adolescent. Tobacco was sold (32.2\%) and given as a gift (67.8\%). Positive correlates of adolescent provision included family availability, best friends and father smoked, purchased cigarettes in the last 30 days, and ownership of tobacco brand merchandise.
\end{abstract}

(C) 2003 Californian Journal of Health Promotion. All rights reserved.

Keywords: adolescent health, tobacco, social sources, commercial sources

Cigarette smoking rates vary among ethnic/racial groups in the United States (CDC, 1998; Livingood, Woodhouse, Sayre, \& Wludyka, 2001). Adolescents obtain tobacco from commercial and social sources. Adolescents perceive that tobacco is readily available and availability is a primary factor for tobacco use onset (CDC, 1995; Florida Department of Health, 1998; Forster, Wolfson, Murray, Wagenaar, \& Claxton, 1997). Adolescent smoking rates remain high among American teens. Over one-third of students smoke by the time they leave high school and one-fifth are smoking monthly by the eighthgrade (Johnston, O’Malley, \& Bachman, 2000). Current cigarette smoking is higher among white (38.6\%), than Hispanic (32.7\%), and Black (19.7\%) students (CDC, 2000). In Philadelphia, results from the 1999 Youth Risk Behavior Surveillance (YRBS) survey showed that $67.9 \%$ of adolescents used cigarettes in their lifetime, $23 \%$ currently used, and $10.3 \%$ were frequent users and use varies by ethnic/racial group (CDC, 2000; Ma, Shive, Legos, \& Tan, 2003).
Primary commercial sources of cigarettes for occasional and regular smokers include gas stations, convenience stores, vending machines, grocery stores, drug stores, stealing, and taverns (Cismoski \& Sheridan, 1993; Forster, KnutInge, \& Jeffery, 1989; Forster et al., 1997; Hinds, 1992). Commercial sources were determined to be an important source of tobacco to minors and efforts were made to restrict youth access. Previous studies have shown that there are racial/ethnic differences in merchant sales to adolescents. In a California study, an analysis of 432 purchase attempts which used Black, White, and Latino adolescent confederates, found that older (16-year-old) Black males and females were the most likely to be sold cigarettes (Klonoff, Landrine, \& Alcaraz, 1997). Clerks were more likely to sell to a minor if that minor was 14-16 years old, Latino, or a 16 year old Black girl or boy, whereas being a Latino boy decreased the likelihood of sales. Black children were sold more packs of cigarettes in Black neighborhoods than White children (Landrine \& Klonoff, 1997). Further, 91\% of cigarettes sold 
to both White and Black children were by nonBlack clerks, and of those packs sold to Black children in Black neighborhoods, 93\% were sold by non-Black clerks. Representative non-Black clerks selling cigarettes to Blacks in Black neighborhoods were Asians (67\%), Whites (12.7\%), and Latinos (13\%). Black (7\%) clerks were the least likely to sell tobacco to Black minors in Black neighborhoods. There are differences in merchant sales of tobacco to different racial/ethnic minors, and in clerks' willingness to sell. It appears that socio-cultural variables play an important role in access to tobacco by minors.

Adolescents can also obtain tobacco from social sources. These social sources include parents, older siblings, other adults, peer friends, and theft (Forster, et al., 1997; Florida Department of Health, 1998; Forster, et al., 1989). The majority of current smokers obtained their first cigarette from family or friends (CDC, 1996; Florida Department of Health, 1998; Forster, et al., 1997; Wolfson \& Forster, 1997). There is a pressing need to address the social availability of tobacco to youth (Wolfson \& Forster, 1997).

One form of social source of tobacco to minors is adolescent provision of tobacco to other adolescents. Friends and family are important sources of tobacco to adolescents (Cummings, Sciandra, Pechacek, Orlandi, \& Lynn, 1992; Forster, et al., 1997; Greenlund, Johnson, Webber, Berenson, 1997) and the source of cigarettes is a function of frequency of use (Emery, Gilpin, White, \& Pierce, 1999). As adolescents progressively smoke more than one cigarette a day, they purchase cigarettes themselves rather than relying on others to give or purchase cigarettes for them. Students perceive that tobacco is easy to get, especially from friends and family (Forster, et al., 1997). A study found that of those students who reported smoking in the past 30 days, $68 \%$ of them reported providing tobacco to another adolescent during that period. Of those that provided tobacco, $66.3 \%$ gave to someone their age, $37.4 \%$ gave to a younger friend, $16.6 \%$ gave to a sibling, and $12.9 \%$ gave to a stranger (Wolfson \& Forster, 1997).
Factors which correlate with adolescent provision of tobacco to other adolescents have included adolescent smokers who: were heavy smokers, had many friends who smoked, had mothers who smoked, owned tobacco related merchandise, and had access to commercial sources (Wolfson \& Forster, 1997). This study suggests that there may be a close relationship between social and commercial availability, a finding supported in previous studies (Hinds, 1992). The authors caution that the results of this cross-sectional study are limited, due to the sample selected. The characteristics of samples of the available research literature tend to emphasize rural, small, homogeneous populations, and typically include students who attend public schools. There is a need to determine sources of tobacco to youth in a large urban, heterogeneous population, to distinguish between gift or sale, and to include students from public and nonpublic schools, such as in Philadelphia. Further, there is a need to address the social availability of tobacco to youth, and to further assess the extent and predictors of adolescent provision of tobacco to other adolescents (Wolfson \& Forster, 1997). Past studies which have investigated the relationship between tobacco use and the various psychosocial factors may not be applicable with other ethnic/racial populations.

The purpose of this study was to examine the sources of tobacco and the adolescent provision of tobacco to other adolescents in an ethnically/ racially diverse and large urban student population in Philadelphia, Pennsylvania.

\section{Methods}

The sample for this study included 569 students from grades 8-10 attending five public $(n=290)$ and nonpublic $(\mathrm{n}=355)$ funded schools in a racially and ethnic diverse part of Philadelphia, Pennsylvania. Students completed a voluntary and anonymous 68-item questionnaire in spring 2000. Grades 8-10 were chosen as the sample for the survey because these students would be no older than 15 or 16 years old and therefore they would be old enough to have started to smoke in large numbers and yet too young to be sold cigarettes legally. A stratified, multistage purposive sampling procedure was used in 
selecting the sample. The diverse section of Philadelphia was chosen to conduct the study, due to the heterogeneity of its culturally diverse population and a health service agency estimated that merchant sales of tobacco to minors was the highest in Philadelphia. Klepp et al. (1996) suggested that a student population be chosen for conducting a study in which tobacco use was a salient issue. Students from public and nonpublic funded schools located in a diverse section of Philadelphia were selected in the sample to be more inclusive and representative of the neighborhood population.

A current list (1997-1998) of schools in the diverse section of a Philadelphia school cluster was obtained from the School District of Philadelphia and the Pennsylvania Department of Education. The primary sampling unit was comprised of students in five (5) schools in the diverse section of Philadelphia, a public funded middle and high school, and two nonpublic funded elementary schools and one high school. Seven schools were approached and 2 did not want to participate. The first stage consisted of selecting neighborhood (few nonresident enrollment) schools that were ethnically/racially diverse. The second stage involved selecting classrooms in the schools to administer the survey. In the high schools, subjects such as Health, Physical Education, English, and Social Studies were chosen because these were required and there was very little overlap of students.

\section{Sample Characteristics}

The sample consisted of $75 \%$ males and $25 \%$ females (Table 1). There was an equal distribution of males (46.7\%) and females (53.3\%) in the eighth grade, but there were more males than females in grades 9-10 due to the unisex character of the nonpublic high school surveyed. The sample included Asians (12\%), African Americans (32.9\%), Hispanics (3.3\%), American Indians (0.7\%), and Whites (50.9\%). Measures of disposable weekly income indicated that $22.5 \%$ had less than $\$ 10$ a week for discretionary income, and 54.8\% had more than $\$ 25$ to spend. The reported level of cigarette use included ever (48.9\%), past month (19.3\%), weekly (17\%), and daily (15.3\%) use (Table 1). More ninth graders indicated that they smoked in these four categories than eighth and tenth graders. On average, smokers reported smoking eight cigarettes daily, and 40 cigarettes weekly. The mean age of initiation for the total sample was approximately 12 years. Smokers were sure that they could quit $(\mathrm{M}=5.0, \quad \mathrm{SD}=2.2)$ and attempted to approximately 2 times in the last year $(\mathrm{M}=1.8,4.2)$.

A discussion of the estimates of reliability and validity were reported elsewhere ( $\mathrm{Ma}$, et al., 2003). Items measuring social and commercial sources of tobacco had good levels of test-retest reliability, based on values of Kappa between 0.40 and 0.75 (SPSS, 1999).

\section{Data Analysis}

Data were analyzed with SPSS version 10.0. The statistical tests used in the data analysis included descriptive statistics, the Phi, contingency, and point biserial correlations, and logistical regression analyses. Descriptive statistics were reported for the demographic variables(gender, race, grade, and disposable income), and smoking behavior (frequency, age of initiation, ability to quit, and quit attempts), perceived availability ( $1=$ very difficult and $7=$ not at all difficult), and sources (commercial or social) of tobacco. Correlations were also reported. The dependent variable was adolescent provision of tobacco to other adolescents in the past month. The independent variables were demographics, social influences (friend or family), perceived sanctions (high, medium, low), perceived availability, source of most recent cigarettes (commercial or social), age of initiation, purchase attempts, number of weekly cigarettes, and ownership of tobacco merchandise. School sanctions were defined as low (nothing to sent to the office), medium (stay after school to required to attend special class), and high (suspended from activities to expelled). 
Table 1

Characteristics of Respondents by Grade

\begin{tabular}{|c|c|c|c|c|}
\hline & \multicolumn{4}{|c|}{ Grade (\%) } \\
\hline & $\begin{array}{l}\text { Grade } 8 \\
(\mathrm{n}=75)\end{array}$ & $\begin{array}{c}\text { Grade } 9 \\
(\mathrm{n}=184)\end{array}$ & $\begin{array}{l}\text { Grade 10 } \\
(\mathrm{n}=310)\end{array}$ & $\begin{array}{c}\text { Total } \\
(\mathrm{N}=569)\end{array}$ \\
\hline \multicolumn{5}{|l|}{ Demographics } \\
\hline \multicolumn{5}{|l|}{ Gender } \\
\hline Male & 46.7 & 77.2 & 80.3 & 74.9 \\
\hline Female & 53.3 & 22.8 & 19.7 & 25.1 \\
\hline \multicolumn{5}{|l|}{ Racial/ethnic group } \\
\hline Asian or Asian America & 2.7 & 10.9 & 14.8 & 12.0 \\
\hline African American or Black & 58.1 & 27.2 & 30.3 & 32.9 \\
\hline Hispanic or Latino & 1.4 & 4.3 & 3.2 & 3.3 \\
\hline American Indian & 1.4 & & 1.0 & 0.7 \\
\hline White & 36.5 & 57.1 & 50.6 & 50.9 \\
\hline \multicolumn{5}{|l|}{ Amount of disposable weekly income } \\
\hline$\leq \$ 10$ & 41.9 & 19.3 & 19.4 & 22.5 \\
\hline$\$ 11-25$ & 27.0 & 27.3 & 19.0 & 22.8 \\
\hline$>25$ & 31.1 & 53.4 & 61.5 & 54.8 \\
\hline \multicolumn{5}{|l|}{ Cigarette Use (\%) } \\
\hline Ever use & 48.0 & 52.2 & 47.2 & 48.9 \\
\hline Past Month & 12.0 & 20.9 & 20.2 & 19.3 \\
\hline Weekly & 8.0 & 20.7 & 17.1 & 17.0 \\
\hline Daily & 8.0 & 19.0 & 14.8 & 15.3 \\
\hline \multicolumn{5}{|l|}{ Smokers (Mean (SD)) } \\
\hline Cigarettes smoked past 24 hours: & $5.0(7.5)$ & 8.3(8.9) & $8.0(6.7)$ & $7.9(7.7)$ \\
\hline Cigarettes smoked past week: & $30.3(49.2)$ & $40.0(52.0)$ & $41.4(42.9)$ & $40.1(46.7)$ \\
\hline Age of initiation: & $10.7(2.0)$ & $11.9(2.3)$ & $12.2(2.1)$ & $11.9(2.2)$ \\
\hline Certain in ability to quit ${ }^{\mathrm{a}}$ & $5.8(1.9)$ & $4.7(2.3)$ & $5.0(2.2)$ & $5.0(2.2)$ \\
\hline Quit attempts: & $1.7(2.3)$ & $2.3(4.5)$ & $1.4(4.2)$ & $1.8(4.2)$ \\
\hline
\end{tabular}

A logistic regression analysis was used to identify potential predictor variables of adolescent provision of tobacco to other adolescents using SAS 8.0. The independent variables were demographics, social influences, perceived sanctions, perceived availability, sources of cigarettes, smoking behavior, and ownership of tobacco brand items. The dependent variable was adolescent provision of tobacco to other adolescents in the last 30 days. Variables were included in the final logistic regression model by forward stepwise selection. The likelihood-ratio(LR) test was used to determine removal of variables from the model at each step. Entry of variables at each step based on .25 and the significance criterion for selection of whether a variable remained in the model was .05 (Allison, 1999). Nagelkerke's Max-rescaled $\mathrm{R}^{2}$ was used to estimate the variation in the outcome variable explained by the logistic regression model (Nagelkerke, 1991; Norusis, 1999).

\section{Results}

\section{Sources of Tobacco}

Smokers perceived that it was easy to get cigarettes from friends, vending machines, and over-the-counter purchases (Table 2). It was difficult to get cigarettes from family members $(\mathrm{M}=3.4)$ and by stealing $(\mathrm{M}=3.0)$ them from a store. Weekly smokers reported that it was not difficult to get cigarettes from friends $(M=6.2)$, vending machines $(M=5.5)$, and through overthe-counter purchases $(\mathrm{M}=5.2)$. Weekly 
smokers $(M=4.1)$ perceived that it was easier to get cigarettes from family members than ever smokers $(\mathrm{M}=3.4)$. Friends accounted for the largest reported source of initial, most recent and ever source of cigarettes. Family accounted for the second largest initial and ever source. Store purchases accounted for the second most recent source. If family and friends are combined as an initial source of tobacco, approximately 93\% of ever smokers obtained cigarettes from social sources, compared with $6 \%$ who obtained them from commercial sources. Less than $1 \%$ reported getting their most recent cigarettes by stealing them from a store. Students were certain in their ability to quit smoking ( $M=5.0$, $\mathrm{SD}=2.2$ ).

Table 2

Sources Of Cigarettes To Ever Smokers By Grade And Weekly Smokers

\begin{tabular}{|c|c|c|c|c|c|}
\hline & \multicolumn{4}{|c|}{ Ever Smokers (\%) } & \multirow[b]{2}{*}{$\begin{array}{l}\text { Weekly Smokers } \\
\quad(\mathrm{n}=93), \%\end{array}$} \\
\hline & $\begin{array}{l}\text { Grade } 8 \\
(\mathrm{n}=36)\end{array}$ & $\begin{array}{l}\text { Grade } 9 \\
(\mathrm{n}=95)\end{array}$ & $\begin{array}{l}\text { Grade } 10 \\
(\mathrm{n}=146)\end{array}$ & $\begin{array}{c}\text { Total } \\
(\mathrm{n}=277)\end{array}$ & \\
\hline \multicolumn{6}{|l|}{ Source of First Cigarette } \\
\hline Friend & 60.0 & 76.5 & 72.4 & 72.0 & 64.5 \\
\hline Family & 28.6 & 16.5 & 20.9 & 20.5 & 24.7 \\
\hline Vending Machine & 0 & 1.2 & 1.5 & 1.2 & 1.1 \\
\hline Over-the-Counter purchase & 5.7 & 3.5 & 2.2 & 3.1 & 3.2 \\
\hline Stolen from business & 0 & 1.2 & 1.5 & 1.2 & 2.2 \\
\hline Other & 5.7 & 1.2 & 1.5 & 2.0 & 2.2 \\
\hline \multicolumn{6}{|c|}{$\begin{array}{l}\text { How long after starting to use tobacco, } \\
\text { purchased own }\end{array}$} \\
\hline Never bought & 53.6 & 39.1 & 42.9 & 43.1 & 8.9 \\
\hline Within month & 42.9 & 42.0 & 38.1 & 40.1 & 62.2 \\
\hline Within year & 0 & 11.6 & 10.5 & 9.4 & 18.9 \\
\hline$>$ Year & 3.6 & 7.2 & 8.6 & 7.4 & 9.5 \\
\hline \multicolumn{6}{|l|}{ Source of most recent cigarette } \\
\hline Friend & 73.1 & 69.5 & 63.0 & 66.5 & 43.0 \\
\hline Family & 15.4 & 11.0 & 9.2 & 10.6 & 8.6 \\
\hline Vending machine & 0 & 2.4 & 0.8 & 1.3 & 3.2 \\
\hline Over-the-counter purchase & 11.5 & 14.6 & 26.1 & 20.3 & 40.9 \\
\hline Stolen from business & 0 & 1.2 & 0.8 & 0.9 & 1.1 \\
\hline Other & 0 & 1.2 & 0 & 0.4 & 1.1 \\
\hline \multicolumn{6}{|l|}{ Attempts to purchase, last 30 days: } \\
\hline None & 86.1 & 74.7 & 69.2 & 73.3 & 44.3 \\
\hline $1-5$ times & 13.9 & 13.8 & 17.8 & 15.8 & 28.9 \\
\hline 6-10 times & 0 & 3.2 & 6.2 & 4.3 & 9.3 \\
\hline$>11$ times & 0 & 8.5 & 6.9 & 6.5 & 17.5 \\
\hline \multicolumn{6}{|l|}{ Ever obtained cigarettes } \\
\hline Friend & 80.8 & 84.1 & 89.5 & 86.6 & 90.2 \\
\hline Family & 38.5 & 39.8 & 43.9 & 41.8 & 71.7 \\
\hline Vending Machine & 11.5 & 28.4 & 22.8 & 23.6 & 47.8 \\
\hline Over-the-Counter & 42.3 & 34.1 & 42.3 & 39.2 & 71.7 \\
\hline Stolen from business & 0 & 9.1 & 4.1 & 5.5 & 8.7 \\
\hline \multicolumn{6}{|l|}{ Type of business ever a source (\%) } \\
\hline Restaurant & 15.4 & 20.0 & 22.6 & 20.9 & 18.5 \\
\hline Gas station/convenience store & 61.5 & 40.0 & 46.8 & 45.2 & 42.4 \\
\hline Grocery store & 30.8 & 37.5 & 37.1 & 36.5 & 32.6 \\
\hline Pharmacy & 15.4 & 17.5 & 22.6 & 20.0 & 17.4 \\
\hline Bar, Tavern, Pub, liquor store & 0 & 10.0 & 19.4 & 13.9 & 14.1 \\
\hline Hotel/motel & 0 & 5.0 & 6.5 & 5.2 & 6.5 \\
\hline
\end{tabular}




\begin{tabular}{|c|c|c|c|c|c|}
\hline & \multicolumn{4}{|c|}{ Ever Smokers (\%) } & \multirow[b]{2}{*}{$\begin{array}{l}\text { Weekly Smokers } \\
\text { (n = 93),\% }\end{array}$} \\
\hline & $\begin{array}{l}\text { Grade } 8 \\
(\mathrm{n}=36)\end{array}$ & $\begin{array}{l}\text { Grade } 9 \\
(\mathrm{n}=95)\end{array}$ & $\begin{array}{l}\text { Grade } 10 \\
(n=146)\end{array}$ & $\begin{array}{c}\text { Total } \\
(\mathrm{n}=277)\end{array}$ & \\
\hline Discount store & 15.4 & 12.5 & 11.3 & 12.2 & 13.0 \\
\hline Recreational/Sports center & 7.7 & 20.0 & 40.3 & 29.6 & 29.3 \\
\hline Other & 15.4 & 5.0 & 3.2 & .2 & 2.2 \\
\hline \multicolumn{6}{|l|}{ Perceived availability $^{\mathrm{a}}$} \\
\hline Friend & 6.3 & 6.1 & 6.2 & 6.2 & 6.2 \\
\hline Family & 3.2 & 3.4 & 3.6 & 3.4 & 4.1 \\
\hline Vending machine & 4.6 & 5.5 & 5.6 & 5.4 & 5.5 \\
\hline Over-the-counter & 4.9 & 4.7 & 4.8 & 4.8 & 5.2 \\
\hline Steal from store & 3.2 & 2.9 & 2.9 & 3.0 & 2.9 \\
\hline
\end{tabular}

Common commercial sources for ever obtaining cigarettes were from gas stations/convenience stores, grocery stores, recreational/sports center, restaurant, pharmacy, bar or tavern, and discount stores. Among ever smokers, 40\% purchased their own cigarettes within a month after starting. Weekly smokers were more likely to have attempted to purchase tobacco in the last 30 days and were also less likely to have the store clerks refuse to sell them cigarettes, than ever smokers.

\section{Adolescent Provision of Tobacco to}

\section{Other Adolescents}

Of the students sampled, $18.6 \%$ reported that they gave tobacco to another adolescent minor in the past month. Among smokers, $45.6 \%$ gave tobacco to another adolescent. Recipients included siblings (4.9\%), same age friend (20.4\%), younger friend $(10 \%)$, and strangers $(10.3 \%)$. Tobacco was sold (32.2\%) and given as a gift $(67.8 \%)$. Further, $17.9 \%$ of students reported that they had been given money to purchase tobacco for another adolescent.

Table 3 shows the correlation between each independent variable with the dependent variable of adolescent provision. The following independent variables were significantly $(\mathrm{p}<$ .05 ) positively correlated with the dependent variable: race, gender, amount of disposable weekly income, whether the father, mother, siblings, and best friends smoke, the number of friends who smoke, and the perceived percentage in the grade who smoke, perceived difficulty of getting cigarettes from family and a salesperson, the most recent source of a cigarette, purchase attempts in the last 30 days, the number of weekly cigarettes smoked, and the ownership of tobacco brand merchandise. Low and medium school sanctions and parental sanctions were significantly $(\underline{p}<.05)$ negatively correlated with the dependent variable.

Table 3

Correlation of Indep. Variables with Adolescent Provision of Tobacco to Other Adolescents ( $\mathrm{N=569)}$

\begin{tabular}{|c|c|}
\hline \multicolumn{1}{|c|}{ Independent Variables } & $\begin{array}{c}\text { Adolescent provision of tobacco } \\
\text { to other adolescents }\end{array}$ \\
\hline Demographics $^{\mathrm{Correlations}}$ \\
\hline Race $^{\mathrm{a}}$ & $.19^{* * *}$ \\
\hline Father's education $^{\mathrm{a}}$ & .09 \\
\hline Mother's education $^{\mathrm{a}}$ & .09 \\
\hline Gender $^{\mathrm{b}}$ & $.14^{* * *}$ \\
\hline Grade $^{\mathrm{a}}$ & .07 \\
\hline Disposable income $^{\mathrm{a}}$ & $.22^{* * *}$ \\
\hline Social Influences & \\
\hline
\end{tabular}




\begin{tabular}{|c|c|}
\hline Independent Variables & $\begin{array}{c}\text { Adolescent provision of tobacco } \\
\text { to other adolescents }\end{array}$ \\
\hline Demographics & Correlations \\
\hline Father smokes ${ }^{\mathrm{b}}$ & $.19^{* * *}$ \\
\hline Mother smokes ${ }^{b}$ & $.19^{* * *}$ \\
\hline Sibling smokes ${ }^{\mathrm{b}}$ & $.20^{* * *}$ \\
\hline Best friend smokes ${ }^{\mathrm{b}}$ & $.40^{* * *}$ \\
\hline Number of friends who smoke ${ }^{a}$ & $.44^{* * *}$ \\
\hline Perceived percentage in grade who smoke ${ }^{a}$ & $.20^{* * *}$ \\
\hline \multicolumn{2}{|l|}{ Perceived Sanctions } \\
\hline Low school sanctions ${ }^{\mathrm{b}}$ & $-.08^{*}$ \\
\hline Medium school sanctions ${ }^{\mathrm{b}}$ & $-.12^{* *}$ \\
\hline High school sanctions $^{\mathrm{b}}$ & -.04 \\
\hline Parental sanctions ${ }^{\mathrm{b}}$ & $-.32^{* * *}$ \\
\hline \multicolumn{2}{|l|}{ Perceived Availability } \\
\hline Difficulty of getting cigarettes from friend ${ }^{\mathrm{a}}$ & .09 \\
\hline Difficulty of getting cigarettes from family ${ }^{\mathrm{a}}$ & $.26^{* * *}$ \\
\hline Difficulty of getting cigarettes from vending machine ${ }^{a}$ & .09 \\
\hline Difficulty of getting cigarettes from salesperson $^{\mathrm{a}}$ & $.13^{* *}$ \\
\hline Difficulty of getting cigarettes from stealing ${ }^{\mathrm{a}}$ & .08 \\
\hline Source of most recent cigarette $^{\mathrm{a}}$ & $.49^{* * *}$ \\
\hline Purchase attempt in last 30 days $^{\mathrm{a}}$ & $.51^{* * *}$ \\
\hline Age initiated smoking ${ }^{\mathrm{c}}$ & .17 \\
\hline Number of weekly cigarettes ${ }^{\mathrm{C}}$ & $.73^{* * *}$ \\
\hline Own tobacco brand products ${ }^{\mathrm{b}}$ & $.21^{* * *}$ \\
\hline
\end{tabular}

Table 4 contains the final logistic regression results. The following variables were all positively associated with adolescent provision of tobacco to other adolescents: family availability (FA), best friends smoked (BFS), best friends do not smoke (BFDS), father smokes (FS), father does not smoke (FDS), purchased cigarettes but not in the last 30 days(PANPM), purchased cigarettes in the last 30 days (PA), and ownership of tobacco brand merchandise (OTM). The logistic regression equation for the probability of adolescent provision of tobacco to another adolescent was: $\mathrm{Z}_{\text {(provision) }}=1.35(\mathrm{FA})+0.92(\mathrm{PANPM})+$ 0.29 (PA) $-0.62($ FDS $)+0.41(\mathrm{FS})-0.08$ (BFDS) $+1.08(\mathrm{BFS})+0.78(\mathrm{OTM})-1.91$. Z represents the linear combination of each correlated variable and is used to calculate the probability of the occurrence of the outcome variable of provision of tobacco. The Max-rescaled $\mathrm{R}^{2}$ was 0.52 which indicates that $52 \%$ of the variance in adolescent tobacco provision is explained by the logistic regression model. 
Table 4

Final Logistic Regression: Predictor Variables of Adolescent Smokers' Provision of Tobacco Products to Other Adolescents

\begin{tabular}{|l|c|c|c|}
\hline \multicolumn{1}{|c|}{$(\mathrm{n}=221)$} & $\begin{array}{c}\text { Coefficient } \\
(\mathrm{SE})\end{array}$ & Odds Ratio & $\begin{array}{c}\text { 95\% Confidence } \\
\text { Interval }\end{array}$ \\
\hline Family availability & $1.35(0.37)^{* *}$ & 3.86 & $1.87,8.18$ \\
\hline Purchased cigarettes, but not last 30 days & $0.92(0.19)^{* * *}$ & $\cdots$ & $\cdots$ \\
\hline Purchase cigarettes in last 30 days & $0.29(0.19)^{* * *}$ & $\cdots$ & $\cdots$ \\
\hline Father smokes & $0.41(0.56)^{*}$ & 1.51 & $0.53,4.67$ \\
\hline Father does not smoke & $-0.62(0.61)^{*}$ & 0.54 & $0.16,1.79$ \\
\hline Best friend smokes & $1.08(0.61)^{*}$ & 2.96 & $0.93,10.55$ \\
\hline Best friend does not smoke & $-0.08(0.64)^{*}$ & 0.93 & $0.27,3.47$ \\
\hline Owns tobacco brand merchandise & $0.78(0.38)^{*}$ & 2.19 & $1.04,4.70$ \\
\hline
\end{tabular}

p $<.05 ;{ }^{* *} \mathrm{p}<.01 ;{ }^{* * *} \mathrm{p}<.001$

The odds that adolescent smokers would provide tobacco were 3.8 times higher if tobacco was perceived to be readily available from family members. The more students indicated that they attempted to purchase tobacco, the greater the odds that they had provided tobacco. The odds of adolescent provision of tobacco were 1.5 times higher if the father smoked compared to a father who had no influence. Those fathers who did not smoke provided a protective factor from adolescents smoking compared to those fathers who had neutral influence. The odds of adolescent provision were 2.2 times higher if the student owned tobacco brand merchandise.

\section{Discussion}

Prevalence of smoking among adolescents in Philadelphia remains high, with approximately $49 \%$ having ever used, $19 \%$ in the past month, $17 \%$ weekly, and $15 \%$ used daily. The TPOP study conducted in Minnesota showed similar findings with 50\% ever smoked, 20\% the last 30 days, $17 \%$ weekly and $11 \%$ smoked daily (Forster, et al., 1997). These findings also lend further support to those studies which have found similarities in adolescent smoking rates in rural and urban locations (Cronk \& Sarvela, 1997). Also consistent with previous literature, the mean age of initiation was 12 years (Johnston, et al., 2000). Overall, smokers were confident in their ability to quit smoking, however, they tried to quit on average less than 2 times in the past month. These findings present a challenge to reducing this health problem. This study shows that while there may be differences in smoking rates between ethnic/racial groups, smokers may share many similar factors related to smoking behavior.

Social sources were the most prevalent source of tobacco to adolescents in Philadelphia. Friends were perceived as the least difficult to get tobacco from, and in fact accounted for the largest reported initial, most recent and ever source of tobacco. Family was a more important initial and ever source of tobacco than commercial sources, lending support to previous studies (CDC, 1995; Forster, et al., 1997; Forster, et al., 1989; Greenlund, et al., 1997; Hinds, 1992). Family members also serve as social influences by imitating behavior and providing norms for use. They are influential in smoking initiation and maintenance of use among children (Jackson, Bee-Gates, \& Henriksen, 1994; Males, 1995). In the current study, mothers were more likely to be reported as a source of tobacco than fathers, an observation made in previous studies (Ahlgren, Norem, Hochhauser, \& Garvin, 1982; Gfroerer, 1987; Kandel \& Wu, 1995). While it is beyond the scope of the design of this study to determine if social sources have increased due to enforcement efforts to reduce commercial access to tobacco as found in other studies (Hinds, 1992), social sources will need to be addressed in tobacco use prevention curricula used in 
Philadelphia. Parents and peers serve as a primary source of tobacco in the sample. Despite increased law enforcement policies, students still perceive that tobacco is readily available, especially from family and friends, but also from commercial sources. Students obtained less tobacco from commercial sources than social, which may be some indication that enforcement of youth restriction laws to reduce commercial access are working.

Commercial sources were also important sources of tobacco for adolescents. Among ever smokers, $40 \%$ reported that they purchased their own cigarettes within one month of starting to smoke. Further, 22.5\% reported obtaining their most recent cigarettes from commercial sources. Types of businesses which served as an ever source included, gas stations/convenience stores (45\%) were the most important sources followed by grocery stores (37\%), recreational/sports centers (30\%), restaurants (21\%), pharmacies (20\%), bars/taverns (14\%), and discount stores (12\%). These findings corroborate the results of previous studies which also found the same predominant commercial sources among small rural populations (Cismoski \& Seridan, 1993; Forster, et al., 1997; Forster, et al., 1989). The present study also found that $26.6 \%$ of ever smokers tried to purchase tobacco from a store in the last 30 days, similar to the TPOP study in Minnesota (26.9\%) (Forster, et al., 1997). Sources of cigarettes is a function of the frequency of use. The greater the quantity of cigarettes used daily, the more likely the adolescent is to purchase them commercially (Emery, et al., 1999). While enforcement of existing laws which prohibit the sale of tobacco to minors in Philadelphia has led to a reduction in sales of tobacco to minors (Jason et al., 1996; Ma, Shive, \& Tracy, 2001), commercial sources are still readily available to minors in Philadelphia.

Among past month adolescent smokers, 46\% gave tobacco to another adolescent. This finding was less than the TPOP study which found that 68\% provided (Wolfson \& Forster, 1997). Since, student's perceptions of the percentage of peers who smoke in their grade is correlated with tobacco provision supports the notion that smoking may be a normative activity. As smoking increasingly is perceived as the norm, adolescents may be more likely to participate in the behavior. Adolescent provision of tobacco to other adolescents appears to be associated with belonging to a particular racial group, of a certain gender, the more disposable income, if family and friends smoke, if the student perceives that many peers smoke, if there are no or few school and parental sanctions, and if it is perceived that it is easy to get cigarettes from family and store clerks, the more cigarettes smoked per week, and whether the person has tobacco brand merchandise.

The independent variables which predicted adolescent provision of tobacco to other adolescents were perceived difficulty of obtaining tobacco from family (difficult, not difficult), best friends smoke, frequency of purchase attempts, father smokes, and ownership of tobacco brand merchandise were all positively associated with provision. These results suggest that, the odds of provision increase if cigarettes are readily available from the family, the higher the frequency of purchase attempts, if friends smoke, if the father smokes, and if the adolescent smoker owns tobacco brand items. These observations support other studies which indicate that adolescents were more likely to provide tobacco if they had many friends who smoke, they owned tobacco brand merchandise, and attempted to purchase tobacco in the last 30 days (Wolfson \& Forster, 1997). Heavier smokers may have the largest supply and the easiest access to tobacco which enable them to give some to others. This study shows that knowledge of a father's tobacco use may influence adolescent provision. These findings also suggest that school and community based programs could include messages that discourage adolescent smokers from providing cigarettes to their friends. In addition, more emphasis will need to be placed on parenting programs which emphasize the role of parental influence in provision of tobacco among adolescents.

This study has several limitations. First, crosssectional data cannot be used to establish cause and effect relationships between smoking 
behavior and sources of tobacco. Second, the sample was restricted to an ethnically/racial heterogeneous urban adolescents who attend schools and so it may not be representative of all adolescents. Throughout this study, the results were compared with the TPOP study conducted in Minnesota to show consistencies across the two populations. While a direct statistical comparison is not possible, there are similarities in tobacco use behavior, sources of tobacco, and knowledge of and attitudes toward youth restriction policy which supports the validity of the findings and usefulness of both studies. Third, logistical regression analysis is useful for interpolation, but caution needs to be exercised in extrapolating to cases or populations beyond the range of observations. The results of this study may apply only to populations which are characteristic of a large heterogeneous urban area.

Despite these limitations, this study examined smoking behavior, tobacco sources, and factors associated with adolescents who provide tobacco to minors, among a large ethnic/racial diverse, urban adolescent population in Philadelphia. Support was given to many of the findings of previous studies which had been conducted with other populations, allowing for more extensive generalization to other populations. Future research could be conducted to determine the dynamics of school and parental sanction implementation on smoking behaviors and social sources, and the role that these sanctions play in determining normative health behaviors.

Cigarette use is the leading cause of preventable death in the United States. Given the current prevalence and long term health consequences of tobacco use, parents, school and government personnel should carefully examine the challenges and opportunities that are available to design interventions which effectively address social sources and influences on tobacco use. This will be necessary to meet the tobacco use reduction objectives of Healthy People 2010.

\section{References}

Ahlgren, A., Norem, A. A., Hochhauser, M., \& Garvin, J. (1982). Antecedents of smoking among preadolescents. Journal of Drug Education, 12, 325-340.

Allison, P. (1999). Logistical regression: Using the SAS system: Theory and application. Cary, NC: SAS. Centers for Disease Control and Prevention. (1995). State laws on tobacco control: United States, 1995. Mortality and Morbidity Weekly Report, 44(SS-6), 1-30.

Centers for Disease Control and Prevention. (1996). Tobacco use and usual source of cigarettes among high school students - United States, 1995. Journal of School Health, 66, 222-224.

Centers for Disease Control and Prevention. (2000). Youth risk behavior survey surveillance - United States, 1999. Mortality and Morbidity Weekly Report, 49(SS-5), 1-104.

Centers for Disease Control and Prevention. (1998). Tobacco use among U.S. racial/ethnic minority groups - African Americans, American Indians and Alaska Natives, Asian Americans, and Pacific Islanders, hispanics. A report of the Surgeon General. Executive summary. Mortality and Morbidity Weekly Report, 47(RR-18), 1-16.

Cismoski, J., \& Sheridan, M. (1993). Availability of cigarettes to under-age youth in Fond Du Lac, Wisconsin. Wisconsin Medical Journal, 92, 626-630.

Cronk, C. E., \& Sarvela, P. D. (1997). Alcohol, tobacco, and other drug use among rural/small town and urban youth: A secondary analysis of monitoring the future data set. American Journal of Public Health, 87, 760-764.

Emery, S., Gilpin, E. A., White, M. M., \& Pierce, J. P. (1999). How adolescents get their cigarettes: Implications for policies on access and price. Journal of the National Cancer Institute, 91, 184186.

Florida Department of Health. (1998). Florida youth tobacco survey: Highlights from pilot program areas, report no. 2. Bureau of Epidemiology, Tallahassee, FL.

Forster, J. L., Knut-Inge, K., \& Jeffery, R. W. (1989). Sources of cigarettes for tenth graders in two Minnesota cities. Health Education Research, 4, 45-50. 
Forster, J. L., Wolfson, M., Murray, D. M., Wagenaar, A. C., \& Claxton, A. J. (1997). Perceived and measured availability of tobacco to youths in 14 Minnesota communities: The TPOP study. American Journal of Preventive Medicine, 13(3), 167-174.

Gfroerer, J. (1987). Correlation between drug use by teenagers and drug use by older family members. American Journal of Drug Alcohol Abuse, 13(1 \& 2), 95-108.

Greenlund, K. J., Johnson, C. C., Webber, L. S., \& Berenson, G. S. (1997). Cigarette smoking attitudes and first use among third through sixth-grade students: The Bogalusa Heart Study. American Journal of Public Health, 87, 1345-1348.

Hinds, M. W. (1992). Impact of local ordinance banning tobacco sales to minors. Public Health Reports, 107, 355-358.

Jackson, C. \& Bee-Gates, D. J., \& Henriksen, L. (1994). Authoritative parenting, child competencies, and initiation of cigarette smoking. Health Education Quarterly, 21, 103-116.

Jason, L., Billows, W., Schnopp-Wyatt, D., \& King, C. (1996). Reducing the illegal sales of cigarettes to minors: Analysis of alternative enforcement schedules. Journal of Applied Behavior Analysis, 29, 333-344.

Johnston, L. D., O'Malley, P. M., \& Bachman., J. B. (2000). Monitoring the future: National survey results on drug use, 1975-1999. Volume I: Secondary School Students (NIH Publication No. 004802). National Institute on Drug Abuse Bethesda, MD.

Kandel, D. B., \& Wu, P. (1995). The contributions of mothers and fathers to the intergenerational transmission of cigarette smoking in adolescence. Journal of Research on Adolescence, 5, 225252.

Klepp, K., Jones-Webb, R., Wagenaar, A. C., Short, B., Murray, D. M., \& Forster, J. L. (1996). Measurement of alcohol and tobacco availability to underage students. Addictive Behaviors: An International Journal, 21, 585-595.

Klonoff, E. A., Landrine, H., \& Alcaraz, A. (1997). An experimental analysis of sociocultural variables in sales of cigarettes to minors. American Journal of Public Health, 87, 823-826.

Landrine, H., \& Klonoff, E. A. (1997). Racial discrimination in minors' access to tobacco. Journal of Black Psychology, 23(2), 135-147.

Livingood, W. C., Woodhouse, C. D., Sayre, J. J., \& Wludyka, P. (2001). Impact study of tobacco possession law enforcement in Florida. Health Education and Behavior, 28, 733-748.

Ma, G. X., Shive, S. E., \& Tracy, M. (2001). The effects of licensing and inspection enforcement to reduce tobacco sales to minors in greater Philadelphia, 1994-1998. Addictive Behaviors: An International Journal, 26(5), 677-687.

Ma, G. X., Shive, S., Legos, P., \& Tan, Y. (2003). Racial/ethnic differences in adolescent smoking behaviors, sources of tobacco, knowledge and attitudes toward restriction policies. Addictive Behaviors: An International Journal, 28, 249-268.

Males, M. (1995). The influence of parental smoking on youth smoking: Is the recent down playing justified? Journal of School Health, 65(6), 228-230.

Nagelkerke, N. J. (1991). A note on a general definition of the coefficient of determination. Biometrika, 78, 691-692.

Norusis, M. J. (1999). SPSS Regression Models 10.0. Chicago, IL, SPSS, Inc.

Statistical Package for the Social Sciences, SPSS Base 10.0 Applications Guide. SPSS, Inc., Chicago, IL, 1999.

Wolfson, M., \& Forster, J. L. (1997). Adolescent smokers' provision of tobacco to other adolescents. American Journal of Public Health, 87, 649-651.

\section{Acknowledgments}

The collection of data for this study was funded by the Barra Foundation. The authors wish to express their gratitude to the Barra Foundation, and the administrators and students of the public and private elementary and high schools that participated in this study. 
Author Information

Steven E. Shive, Ph.D., M.P.H., Assistant Professor* Department of Health

School of Health Sciences and Human Performance

East Stroudsburg University

DeNike Hall

200 Prospect St.

East Stroudsburg, PA 18301

Tel: 570-422-3330

Fax: 570-422-3848

E-Mail: sshive@po-box.esu.edu

Grace Xueqin Ma, Ph.D., CHES, Associate Professor

Principal Investigator and Director,

ATECAR: Center for Asian Health

Department of Public Health

Temple University

304A Vivacqua Hall

P.O. Box 2843

Philadelphia, PA, USA 19122- 0843

Fax: 215-204-1854

E-mail: grace.ma@temple.edu

Patricia M. Legos, Ed.D., Professor

Department of Public Health

Temple University

304 Vivacaqua Hall

P.O. Box 2843

Philadelphia, PA, USA 19122-0843

Fax: 215-204-1854

E-mail: rose@astro.temple.edu

Earl Shive, Ed.D., CHES, Professor Emeritus

Department of Health

East Stroudsburg University

DeNike Hall

200 Prospect Street

East Stroudsburg, PA 18301

Fax: 570-422-3848

E-mail: eshive1@juno.com

* corresponding author 